\title{
Poésie/Poetry 므므므므믐ㅁㅁㅁㅁㅁㅁㅁㅁㅁ므믐ㅁ므므므므므므므므므므
}

Anne-Marie Alonzo est née à Alexandrie, en Egypte, le 13 décembre 1951. Elle vit au Québec depuis 1963. On lui doit treize livres, dont Bleus de mine qui lui a valu le Prix Emile-Nelligan en 1985. Depuis 1987: elle a publie Ecoute, Sultane et Le livre des ruptures aux Editions de l'Hexagone. Anne-Marie Alonzo est également cofondatrice et codirectrice de la revue et des Editions TroIs. En 1987, elle fonde Les Productions A.M.A., une entreprise de livres-cassettes, dont elle assure la direction.

\section{Oeuvres:}

Geste; fiction (Paris: Des Femmes, 1979); Veille: fiction, (Paris: Des Femmes, 1982); Blanc de thé: livre-objet, d'après une réalisation et une conception graphique de Azélie, Zee Artand (Montréal: Les Zéditions élastiques, 1983); Droite et de profil, fiction (Montréal: Lèvres Urbaines, 7, 1984); Une lettre rouge orange et ocre: texte dramatique (Montréal: La Pleine lune, 1984); Bleus de mine, fiction (Saint-Lambert: Le Noroît, 1985). Ecoute, Sultane, fiction (Montréal:

l'Hexagone, 1987); Seul le désir, fiction (Montréal: NBJ Editeur, 1987); Esmä; fiction (Montréal: NBJ Editeur, 1987); Le livre des ruptures, fiction (Montréal: l'Hexagone, 1988); Lettres à Cassandre, cassette-audio, en collaboration avec Denise Desautels (Laval: Les Productions A.M.A., 1990); L'immobile, fiction épistolaire (Montréal: l'Hexagone, 1990).

\section{II m'arrive d'hésiter}

pour Margie Gillis

Parce qu'au bout des doigts surgit l'empreinte.

Parce qu'au bout comme des doigts s'effilent des jambes sous une boule/belle/boule sous une jupe crinoline des pieds. 
Roule roule et roule cette jupe cree cercle de soie marche cette jupe et seule.

Il y a cela.

Décapitée la jupe marche de l'intérieur une femme pousse de l'intérieur cachée comme enfant qui pousse.

Pour arriver enfin naître.

Ou advenir.

Toute l'histoire serait dite raconté-sous une jupe décapitée mais rien n'est simplement dit.

D'une jupe sans tête grandit un corps.

Long corps de femme mince corps musclé corps nu de la taille au cou de la taille-vue de dos-à la nuque le corps se dévêt prend la jupe pour armure la fait glisser la tire la pousse encore et.

Un arrêt de mouvement arrêt de musique.

Tire-et-pousse-et-donne-des-ailes.

Fait ronde et danse fait croyance de mouvement.

J'ai vu cela.

Je dis que je l'ai vu.

Il m'arrive d'hésiter.

Je vois la poitrine dans l'ombre des ombres et ombres des scènes un filtre caresse la peau dos d'adolescent muscles

petits autour des épaules omoplates côtes.

Je la reconnais de dos uniquement.

Elle est moi sûre de ce que je vois dans l'ombre des ombres sûre de voir troublée d'être si sûre d'avoir vu ne vois plus

et vois encore elle aime jouer je regarde sans jouer de peur

de perdre si le jeu trop fort trop flou trop loin pour moi

elle se perd me gagne souvent m'enlève je deviens

voile

à ses bras elle me porte me souleve me jette me retient avec toi dis-je il y a la danse-et-le-mouvement avec toi la vie à fendre.

Je prie cela. 
Il y a la jupe

Evidemment la jupe.

Et la tête montrée la tête comme signal de larmes les bras nus le torse de dos de dos ce torse je dis: le torse!

Et la chevelure.

Plus longue que tourment cette chevelure chevalline non plus accessoire mais partenaire/danseuse coup d'épaule de rein tour de cou de bras tu danses à côté les yeux par milliers figes je l'approche lui dis: les yeux!

Ecoute! Il y a aussi ce que tout le monde saisit.

Tu danses!

Je ne raconte pas que moi aussi moi il y a 23 ans 10 mois 8 jours 14 heures justes.

Une minuscule maison de danse au fond d'un parc en pays arabe un tutu bleu de roses ballerines elle s'appellait Maria.

Il y aura toujours son parfum en mémoire et parquets cirés.

Alors que toi sous la chevelure diaphane des bonds de fauve un regard d'enfant et cette jupe décapitée jupe roulante comme moi. 